\title{
ANÁLISE SEMÂNTICO-ENUNCIATIVA DE SENHORIO NO ÂMBITO DA FAMÍLIA PATRIARCAL: O NOME E A TRANSMISSÃO DE BENS
}

\section{SEMANTIC-ENUNCIATIVE ANALYSIS OF SENHORIO IN THE PATRIARCAL FAMILY: THE NAME AND TRANSMISSION OF GOODS}

Liliana de Almeida Nascimento FERRAZ1

Jorge Viana SANTOS ${ }^{2}$

Resumo: Neste artigo, analisamos sentidos da palavra senhor circulantes em cartas de alforria no Brasil durante o período de 1841 a 1888 e em textos da imprensa baiana durante o período de 1870 a 1888. Procura-se responder à questão Como se caracteriza semanticamente o senhorio no âmbito da família patriarcal brasileira? Para tanto, mobilizando pressupostos da Semântica do Acontecimento, aliados a alguns princípios da História/Historiografia, analisa-se um corpus de cartas de alforria e textos da imprensa baiana do século XIX. Demonstra-se, com base nos dados, que o senhorio brasileiro apresenta sentidos específicos fundamentados não somente na relação senhor-escravo, mas também no poder do senhor exercido no âmbito da família patriarcal.

Palavras-chave: Semântica do Acontecimento. Escravidão. Senhor. Família.
Abstract: In this article, we analyze the meanings of the word senhor in manumission letters in Brazil during the period 1841-1888 and in the Bahia press texts during the period 1870-1888. We aim to answer the question How is characterized semantically the senhorio in Brazilian patriarchal family? For this, mobilizing the assumptions of Semantic of the Event, together with some principles of History/Historiography, we analyze a corpus of manumission letters and texts of the Bahia press of the nineteenth century. We show that the Brazilian senhorio has specific meanings based not only on the master-slave relationship but also based in the power of the senhor exercised in the patriarchal family.

Keywords: Semantics of Event. Slavery. Slaveholder. Family.

1 Universidade Estadual do Sudoeste da Bahia (UESB), Vitória da Conquista, Bahia, Brasil; liliana.ferraz@enova.educacao.ba.gov.br; http://orcid.org/0000-0003-2266-5356

2 Universidade Estadual do Sudoeste da Bahia (UESB), Vitória da Conquista, Bahia, Brasil; viana.jorge.viana@uesb.edu.br; http://orcid.org/0000-0002-8548-4379 
- Análise semântico-enunciativa de senhorio no âmbito da família patriarcal: o nome e a transmissão de bens

\section{Introdução}

Historicamente, o senhorio no Brasil escravocrata se caracterizou de maneira diferente de outros senhorios, justamente porque se constituiu através da reconfiguração de características que fundamentaram o senhorio em funcionamento em outras sociedades separadas no tempo e no espaço, seja aproximando-se dessas características, que no Brasil também estiveram em funcionamento, a exemplo do patriarcado, do patronato, e da alforria, seja diferenciando-se dessas características, a partir do momento em que elas tiveram no Brasil uma nova configuração, constituindo assim especificamente um senhorio brasileiro.

Dessa maneira, o senhorio brasileiro não se define apenas na relação senhorescravo, mas se constrói como uma estrutura abstrata que abarca diferentes características no interior, por exemplo, do patriarcado, subordinando na figura do senhor diferentes instâncias. Freyre (1933, p. 38) reitera essa afirmação ao apontar que "[...] A força concentrou-se nas mãos dos senhores rurais. Donos das terras. Donos dos homens. Donos das mulheres. Suas casas representam esse imenso poderio feudal".

A figura do senhor agrupou, desse modo, sobre a base econômica da riqueza agrícola e do trabalho escravo, uma variedade de funções sociais e econômicas. O patriarca e, portanto, senhor, mantinha, a partir do domínio, o poder senhorial manifestado em diversas instâncias, através de papéis exercidos, entre outras, na esfera familiar, políticojurídica, econômica, administrativa, e na esfera de preservação e transmissão das tradições.

Apoiando-se nessas premissas, analisaremos neste trabalho ${ }^{3} \mathrm{o}$ senhorio relacionado ao poder do senhor evidenciado no âmbito da família, metodologicamente buscando, pois, resposta para a seguinte questão: Como se caracteriza semanticamente $o$ senhorio no âmbito da família patriarcal brasileira? Para tanto, mobilizando pressupostos da Semântica do Acontecimento, conforme Guimarães (1989, 1995, 2002, 2011) aliados a alguns princípios da História/Historiografia, analisa-se um corpus de 37 cartas de alforria ${ }^{4}$ originais de Vitória da Conquista - Bahia, do século XIX, abrangendo o período de 1841 até o ano de 1888, e analisa-se também um corpus constituído de 36 textos da imprensa

\footnotetext{
3 Este artigo vincula-se ao projeto de pesquisa de doutorado intitulado Sentidos de senhorio na legislação sobre a escravidão africana no Brasil integrante do projeto temático Sentidos de escravidão, liberdade e trabalho coordenado por Jorge Viana Santos e apresenta resultados parciais dos projetos FAPESB APP0014/2016, APP0007/2016 e CNPq 436209/2018-7.

4 Utilizamos aqui exemplos de cartas de liberdade constantes em Ferraz (2014). O acesso a esse corpus foi possível devido ao projeto que vem sendo desenvolvido na Universidade Estadual do Sudoeste da Bahia, denominado Dovic (Documentos Oitocentistas de Vitória da Conquista) (SANTOS; NAMIUTI, 2014), que visa à formação de corpora com informações textuais dos séculos XIX e XX. Para mais detalhes, ver Ferraz (2014).
} 
baiana ${ }^{5}$ do século XIX especificamente nos jornais Correio da Bahia, edições de 1870 a 1879 e O Asteróide em edições de 1887 a 13 de Maio de 1888, considerando, nessa análise, dois aspectos: 1) a estrutura linguística/lexical do nome do senhor em oposição à estrutura do nome de escravo; e 2) a transmissão dos bens aos herdeiros como forma de preservação e manutenção da posse dentro da família.

\section{Considerações teórico-metodológicas}

Tentando compreender como o senhorio se constitui linguisticamente, tomamos como corpus para este trabalho, como já dissemos, textos de duas naturezas: cartas de liberdade e textos da imprensa baiana, do tipo jornal, do século XIX. Tais textos, em conjunto, e cada um a seu modo, são lugares de constituição dos sujeitos, da sociedade e da história, pois materializam e, ao mesmo tempo, silenciam sentidos circulantes na sociedade. Considerando que tal corpus são documentos que, sendo institucionais, voltados para um público específico, registram relações historicamente definidas, mobilizamos teorias de duas áreas: Linguística e História. Do ponto de vista linguístico, utilizamos como teoria principal para análise a Semântica do Acontecimento, tal como postulada por Guimarães $(1989,1995,2002,2011)$, cujo pressuposto fundamental é que a língua materializa nos textos, que integram enunciados ${ }^{6}$, as relações entre os sujeitos e suas respectivas posições, demonstrando que a língua é constitutivamente histórica; além disso, numa perspectiva também da Semântica, recorremos aos conceitos de liberdade transitiva e intransitiva tal como postulados por Santos (2008). Do ponto de vista histórico, dada a natureza do corpus, mobilizamos conceitos/pressupostos de história/historiografia relacionados tanto ao Brasil, quanto a outras sociedades escravocratas.

As cartas de liberdade são instrumentos em que é possível observar um funcionamento semântico específico da palavra senhor ${ }^{7}$, porque são textos escritos pelos próprios senhores. Para o senhor, a carta tinha, de acordo com Santos (2008, p. 45), uma finalidade fundamental: controlar os escravos. Essa finalidade estava ligada, segundo o

\footnotetext{
5 Utilizamos aqui exemplos de textos de jornais baianos constantes em Ferraz (2014). O acesso aos jornais baianos utilizados como fontes de textos para a análise foi possível graças ao funcionamento da Hemeroteca Digital Brasileira, portal de periódicos nacionais vinculado à Fundação Biblioteca Nacional. O acervo da hemeroteca baseia-se na digitalização de documentos que inclui desde os primeiros jornais criados no Brasil no século XIX a jornais extintos no século XX. Para mais detalhes, ver Ferraz (2014).

6 Guimarães (2011, p. 43) ressalta que o texto não é um conjunto de enunciados, ele integra enunciados, de forma que a relação de integração é aquela que constitui sentido.

7 No texto, a palavra senhor está grafada em itálico quando se referir à palavra em análise.
} 
- Análise semântico-enunciativa de senhorio no âmbito da família patriarcal: o nome e a transmissão de bens

autor, a três outras auxiliares: a demonstração de poder soberano ${ }^{8}$; perpetuação da dependência e servilismo; investimento comercial. Nesse sentido, ela representava um eficaz instrumento de controle social, permitindo ao senhor manter sua ascendência tanto sobre o escravo quanto sobre o liberto.

Por serem documentos em que o senhor concede a liberdade ao escravo e geralmente eram os senhores ou seus representantes que as escreviam, as cartas eram constituídas a partir da perspectiva do senhor. Isso caracteriza a carta, enquanto texto privado de cunho individual que expressa diretamente o senhorio, constituindo-se assim como um bom lugar para a análise do funcionamento semântico da palavra senhor.

Os jornais, diferentemente das cartas, constituíam-se como textos públicos de cunho narrativo e de caráter social, nos quais o senhorio era caracterizado pela sociedade a partir de diferentes posições. Por conta disso, decidimos buscar nesses textos sentidos para a palavra senhor, pressupondo que outros sentidos poderiam ser encontrados na análise, já que tais textos não se ligavam diretamente ao lugar de dizer do senhor ou do escravo.

Considerando o corpus apresentado, e tendo que fazer um recorte de natureza linguística para a análise, optamos por priorizar, como questão-chave, a enunciação como acontecimento, considerando que os sentidos de senhor não estão fixos na palavra, mas se dão através da relação com o sujeito que enuncia, com o social e com a história, entendida aqui não como temporalidade cronológica.

Dessa maneira, para a análise específica que fizemos, interessou-nos particularmente a caracterização que realizamos a partir dos pressupostos da Semântica do Acontecimento tal como postulada em Guimarães (1989, 1996, 2002, 2011) que nos permitiram considerar que o senhorio se constitui pelo próprio modo de enunciar nas cartas de liberdade e textos da imprensa baiana do século XIX.

Nessa perspectiva, cada texto se constitui como um acontecimento enunciativo. Esse entendido como:

[...] diferença na sua própria ordem. E o que caracteriza a diferença é que o acontecimento não é um fato no tempo. Ou seja, não é um fato novo enquanto

\footnotetext{
8 De acordo com Mattoso (1982, p. 198) as cartas de alforria são reflexo nítido da mentalidade dos senhores que, numa sociedade escravista, não teriam qualquer necessidade de justificar a liberdade concedida, sempre queriam convencer-se de que agiam de acordo com o bom direito e a estrita equidade. Por isso, nas cartas, é frequente, conforme destaca Santos (2008, p. 46) o uso de expressões formulares, tais como, "pelos bons serviços que della tenho recebido he de minha livre vontade, sem constrangimento de pessoa alguma".
} 
distinto de qualquer outro ocorrido antes no tempo. O que caracteriza como diferença é que o acontecimento temporaliza. Ele não está num presente de um antes e de um depois no tempo. O acontecimento instala sua própria temporalidade: essa é a sua diferença. (GUIMARÃES, 2002, p. 12).

Assim, o acontecimento enunciativo é também político, já que o funcionamento da língua, enquanto acontecimento, ocorre numa "[...] relação com línguas e falantes regulada por uma deontologia global do dizer em uma certa língua" (GUIMARÃES, 2002, p. 18). O autor ressalta que tais falantes não são os indivíduos que falam, mas sujeitos divididos por seus direitos ao dizer e aos modos de dizer, sujeitos constituídos por este espaço de línguas e falantes que ele chama de espaço de enunciação, e que é, portanto, um espaço político (cf. GUIMARÃES, 2002, p. 18).

A partir dessa concepção de político, e nesses espaços de enunciação, a assunção da palavra se dá através de cenas enunciativas que são definidas pelo semanticista como "[...] especificações locais nos espaços de enunciação" (GUIMARÃES, 2002, p. 23), que colocam em jogo o Locutor que aparece predicado por um lugar social, assumindo o papel enunciativo de um locutor específico, como o locutor presidente, o locutor jornalista, etc. e também os enunciadores que se apresentam sempre como a representação da inexistência dos lugares sociais de locutor (cf. GUIMARÃES, 2002). Dessa maneira, os enunciadores não são pessoas, mas lugares enunciativos produzidos pela língua em funcionamento, isto é, trata-se do agenciamento enunciativo. A distribuição desses lugares é determinada pela temporalidade própria do acontecimento, temporalidade formada pelo presente do acontecimento e pelo memorável, que é o passado recortado também pelo acontecimento (cf. GUIMARÃES, 2002).

A partir dessas considerações, vimos, de acordo com Guimarães (2002), que a significação de um nome é entendida como designação, não como algo abstrato, mas sim como algo próprio das relações de linguagem, ou seja, uma relação linguística remetida ao real e tomada na história. Dessa maneira, a designação de um nome é constituída pelas relações com outros nomes que funcionam no texto sob a aparência da substitubilidade e também pelos modos de se referir a ele que são maneiras de determiná-lo e/ou de predicá-lo.

Nesse sentido, para se chegar à designação de um nome, é necessário fazermos recortes de análise, levando-se em conta, de acordo com Guimarães (2002, 2007, 2009), dois funcionamentos gerais próprios do acontecimento: as relações de articulação e as relações de reescrituração. Essas operações enunciativas se caracterizam como agenciamentos específicos, pelos quais "[...] o acontecimento do dizer mobiliza a língua 
- Análise semântico-enunciativa de senhorio no âmbito da família patriarcal: o nome e a transmissão de bens

em textualidades particulares" (GUIMARÃES, 2007, p. 130), deixando marcas que se apresentam como diferenças no fio da textualidade.

Guimarães (2009, p. 51) conceitua a articulação como o "procedimento pelo qual se estabelecem relações semânticas em virtude do modo como os elementos linguísticos, significam sua contiguidade". Esse procedimento coloca em jogo combinatórias de relações entre palavras ou expressões, em que não há substituição, mas sim elementos de sentido que se relacionam no acontecimento. Já a reescrituração consiste, de acordo com Guimarães (2009, p. 53), em "se redizer o que já foi dito", ou seja, trata-se de um procedimento em que uma expressão linguística reporta-se a outra interpretando-a como diferente de si. Em oposição à articulação, esse procedimento não é, necessariamente, uma operação entre elementos contíguos, é uma relação de elementos que estão à distância e que às vezes podem estar contíguos. De acordo com Guimarães (2002, 2007, 2009), levando-se em conta esses dois funcionamentos, chega-se ao que determinado nome designa em textos específicos.

Dada a natureza do corpus, mobilizamos nas análises alguns princípios da história/ historiografia, dentre estes os conceitos de patriarcado, sucessão e hereditariedade. Freire (1933) salienta que a família colonial centrada no patriarca, diferentemente de outras sociedades, estabeleceu-se no Brasil como uma estratégia de colonização portuguesa, não se efetuando pela dominação religiosa, como em outras sociedades ${ }^{9}$. No Brasil, a família do senhor implicava autoridade e hierarquia. Nela, o pai tinha direito de exigir o respeito e a obediência cega dos filhos, esposa, empregados, escravos e dependentes, em troca de sustento, orientação e proteção (cf. SCHWARTZ, 1988). E essa dominação passava de pai para filhos, como veremos nas análises.

\section{Análise e discussão}

Conforme apontamos na introdução, na sociedade escravocrata brasileira, a figura de senhor era a referência a partir da qual se organizavam as diversas relações não somente entre senhor e escravo, mas entre senhor e propriedade, senhor e família, senhor e política, entre outros. Para o recorte deste trabalho, analisaremos, a partir da palavra senhor e sob a perspectiva teórica apresentada acima, como semanticamente se caracteriza o senhorio brasileiro na escravidão no âmbito da família patriarcal. Para tanto, trataremos de dois aspectos: 1) a estrutura linguística/lexical do nome do senhor em oposição à estrutura do nome de escravo; 2) a transmissão dos bens aos herdeiros como forma de preservação e manutenção da posse dentro da família.

9 Na Grécia e em Roma, o patriarcado está ligado à religião e aos deuses de cada família. 


\section{Diferença na estrutura linguística/lexical do nome do senhor em oposição à estrutura do nome de escravo}

Tanto nas cartas, quanto nos textos dos jornais, a nomeação de senhores e escravos apresenta uma estrutura de sentido que diferencia no contexto da escravidão quem é senhor e quem é escravo. Os dados evidenciaram a existência do funcionamento semântico de duas estruturas simétricas: de um lado uma estrutura para o nome de senhor e, por outro lado, uma estrutura para o nome de escravo.

\section{O nome de senhor}

O nome de senhor caracteriza-se estruturalmente por apresentar o nome seguido por um sobrenome de família. Vejamos esse funcionamento através de dois exemplos.

O exemplo 1 trata de um excerto retirado de uma carta de liberdade. Vejamos:

(1) Carta de liberdade da Cabra de nome Sofia passada por Antonio Jose de Souza Paes, outrora Senhor daquela. (Carta 2910: livro 1, folhas 40v-41f, 21/10/1841 - DOVIC, grifo nosso"1).

Verifica-se em 1, no trecho passada por Antonio Jose de Souza Paes, que o locutorsenhor enuncia seu nome através da seguinte estrutura: nome próprio (Antônio Jose) + sobrenome de família (de Souza Paes). O sobrenome indicativo de família remete ao sentido de que se trata de um senhor, branco e livre. O nome enunciado, seguindo essa estrutura, materializa linguisticamente a diferença semântica entre senhor e escravo: o sobrenome no regime escravista só poderia aparecer ao lado do nome de homem branco. Desse modo, Antonio Jose de Souza Paes era senhor e, na carta, marcava essa diferença.

Uma variação dessa estrutura de base (nome + sobrenome) pode ser vista no segundo exemplo recortado do jornal Correio da Bahia:

\footnotetext{
10 As referências dos exemplos de cartas de liberdade seguem a seguinte estrutura: número da carta, número do livro de registro no arquivo do fórum, folhas do livro em que aparece, data de registro do documento no fórum, e em qual arquivo digital se encontra.

11 Neste e nos demais exemplos, salvo indicação em contrário, os grifos são nossos.
} 
- Análise semântico-enunciativa de senhorio no âmbito da família patriarcal: o nome e a transmissão de bens saído de logar denominado Canoa em companhia de uns de seus amigos. Ao aproximar do arroio d'El-rei no dia 26, às 2 horas da tarde, a cavalhada investira para atravessar o dicto arroio fora do passo, pelo que os cavalleiros viram-se forçados a acompanha-la, e com dificuldade transpozeram o rio [...] (Correio da Bahia' ${ }^{12}$, edição 220, p. 2, 18 de Dezembro de 1873 - Hemeroteca digital da Biblioteca Nacional13).

Observa-se em 2, no enunciado Fallecera também desastradamente o sr. Trajano Augusto da Silva. O sr. Trajano tinha saído de logar denominado Canoa, que o nome do senhor, Trajano Augusto da Silva, é reescriturado por sr. Trajano. Nota-se que o locutorjornalista ao reescrever o nome do senhor sem o sobrenome de família, adjetiva esse nome com a abreviação sr., não deixando dúvidas, para o leitor, de que se trata de um senhor e não de um escravo, já que um escravo, se fosse esse o caso, poderia ser referenciado apenas por Trajano, um nome sem sobrenome.

Sistematicamente no corpus, o nome de senhor se apresenta com essa estrutura, de forma que não houve registros em que o nome de senhor apareceu sem a indicação do nome de família. Tal recorrência confirma, pois, que a estrutura de nome de senhor marcava sua hierarquia superior na sociedade. Isso porque o sobrenome que determina o nome próprio especifica algo sobre o que se nomeia" (GUIMARÃES, 2002, p. 34), ou seja, materializa uma relação social de pertencimento a uma família. Nesse caso, uma família que funcionava como um núcleo na estrutura social do período escravocrata, composto pelo chefe da família (patriarca), sua mulher, filhos e netos, que detinham riqueza, poder e prestígio naquela sociedade.

\section{O Nome de escravo}

Os dados evidenciaram, simetricamente, que nome de escravo apresenta uma estrutura que se subdivide em três, as quais detalharemos a seguir:

12 As referências dos exemplos dos excertos recortados dos jornais seguem a seguinte estrutura: nome do jornal, número da edição, página em que aparecem no jornal e a data da edição.

13 A Hemeroteca Digital Brasileira é um portal de periódicos nacionais vinculado à Fundação Biblioteca Nacional no qual encontramos um acervo digitalizado de jornais brasileiros que inclui desde os primeiros jornais criados no Brasil no século XIX a jornais extintos no século XX. Neste portal, é permitido ao pesquisador ampla consulta, pela internet, ao acervo de periódicos, e pode ser realizada por título, período, edição, local de publicação e palavra(s) através da utilização da tecnologia de Reconhecimento Ótico de Caracteres (Optical Character Recognition - OCR), que permite maior alcance na pesquisa textual na imagem dos documentos. Além disso, páginas pesquisadas podem ser impressas ou salvas pelo pesquisador. 


\section{a) Estrutura 1}

A primeira estrutura de nome de escravo apresenta o nome de escravo seguido de outro nome referindo-se à raça/cor/etnia como uma espécie de sobrenome. Santos (2008) afirma que era comum que se documentasse o nome do escravo, acompanhado de um adjetivo que determinava direta ou indiretamente a raça/cor/etnia. Veremos o funcionamento dessa estrutura através de dois exemplos.

Observemos o primeiro excerto recortado de uma carta de liberdade:

(3) Carta de Liberdade de Adrianna Mulata, conferida pelo seu Patrono Agostinho Gonçalves Barbace-na, e sua mulher Neiacia Maria da Paixão, como abaixo declara [...] (Carta 37: livro 1, folhas 101v-102f-103v, 21/10/1845- DOVIC).

Em 3, na sequência Adrianna Mulata, Mulata funciona como um sobrenome (inclusive grafado em maiúsculo) que se articula ao nome como uma adjetivação de cor que especifica indiretamente a raça e, ao mesmo tempo, marca a diferença da escrava em relação ao senhor. O sobrenome raciall', ao determinar o nome, indica que a escrava pertence ao grupo (não à família) de pessoas que, naquele momento histórico - Brasil Escravista do Século XIX - é escrava porque é negra (vinda de determinado lugar - África tendo certa cor, mulata: uma variação de preta). Observa-se, pelo exemplo, que já há um uso corrente de se grafar o nome e o sobrenome com letra inicial maiúscula (como em Agostinho Gonçalves Barbacena). Logo, colocando-se um nome de raça/cor/etnia/ com letra maiúscula marca-se que o sobrenome de escravo, em oposição ao de senhor, é a raça, a cor ou a etnia.

No corpus, encontramos essa mesma estrutura com variação caracterizada como nome + adjetivo, separado por uma pausa. Vejamos isso no segundo exemplo:

(4) Felisberto Pereira Leal, procurador de Joaquim Barbosa; pedindo o prazo de 4 meses, a fim de que possa provar o domínio que tem aquele Barbosa sobre o escravo Manuel, pardo [...] (Correio da Bahia, edição 26, p. 2, 24 de Abril de 1878 - Hemeroteca digital da Biblioteca Nacional).

Note-se, em 4, que o item lexical Manuel aparece articulado ao item lexical pardo que, separado por uma pausa (uma vírgula), funciona como um aposto que caracteriza a cor do escravo e consequentemente a sua condição na sociedade escravocrata. Ser qualificado como pardo remete, inexoravelmente, a uma condição de escravo (ou

14 Termo usado por Santos (2008). 
- Análise semântico-enunciativa de senhorio no âmbito da família patriarcal: o nome e a transmissão de bens

liberto). A estrutura de nome, tal como essa, materializava, portanto, o lugar do escravo, hierarquicamente abaixo do senhor.

\section{b) Estrutura 2}

A estrutura 2 do nome de escravo é caracterizada por apresentar a raça/etnia/cor, seguida de nome de batismo que aparece na posição de sobrenome, como é o caso do excerto abaixo:

(5) Carta de liberdade da Cabra de nome Sofia passada por Antonio Jose de Souza Paes, outrora Senhor daquela.

Eu Antonio Jose de Souza Paes abaixo assignado, sou possuidor da Cabrinha Sofia [...]

(Carta 29: livro 1, folhas 40v-41f, 21/10/1841 - DOVIC).

Vê-se aqui que, na sequência Cabra de nome Sofia, o item Cabra grafado em maiúsculo funciona como um núcleo que é articulado e adjetivado pela sequência de nome Sofia, que caracteriza a escrava especificando sua raça ${ }^{15}$. Nessa estrutura, o locutor mobiliza um enunciador que aponta para o que era mais importante ressaltar, qual seja, a raça do escravo. No corpo da carta, essa posição argumentativa se repete, pois Cabra de nome Sofia é reescriturado por Cabrinha Sofia, que estruturalmente se formou a partir do radical cabr-seguido do sufixo -inha. Essa reescritura traz dois pontos importantes. Em primeiro lugar, vemos que Cabrinha não funciona nesse enunciado como um diminutivo com valor afetivo, nos termos de Câmara (1987); ao utilizar esse item lexical, o locutor não objetiva transmitir sentimentos sobre a escrava. Em segundo lugar, ressalte-se que o diminutivo semanticamente não indica que se trata de uma escrava de estatura pequena. Ao enunciar cabrinha, o locutor-senhor quer marcar a idade da escrava que está sendo alforriada, ou seja, quer indicar quem era a escrava (se era nova, velha, a origem, etc.). Ao fazer essa indicação, o enunciado materializa linguisticamente que o locutor-senhor se coloca como dono da escrava, aquele que - só ele - pode escrever, determinar numa carta, como vemos no exemplo, quem era o escravo.

\section{c) Estrutura 3}

A terceira e última estrutura de nome de escravo encontrada no corpus se caracteriza por apresentar o indicativo da classe (escravo/liberto/forro) acompanhado do nome de batismo. Nessa estrutura, o nome do escravo é apresentado como uma

15 Conforme Santos (2008, p. 166-167), cabra designava escravos de ascendência mista, porém indefinida. 
especificação, um adjetivo articulado à palavra escravo que funciona como núcleo. Exemplificaremos essa estrutura a partir de três excertos.

No excerto 6, recortado de uma carta de liberdade, destaquemos a sequência escravo Cezário:

(6) [...] Eu abaixo assignado, de minha livre e expontanea vontade, cêdo o favor da liberdade do escravo Cezario, todo direito e acção que sobre elle tenho como herdeiro cessionário do fallecido Clemente Ferreira da Rocha - vulgo Clemente Murango [...] (Carta 120: livro 21, folha 60 f, 04/10/1886 - DOVIC).

Verifica-se, em 6, que escravo, termo genérico que indica, nessa sociedade, uma classe, aparece na expressão liberdade do escravo Cezario ocupando a posição nuclear, sendo, portanto, apenas determinado à direita por Cezário, de forma que Cezário, um nome próprio, ao invés de ser um termo nuclear, é apenas uma caracterização do termo principal escravo.

Essa mesma estrutura está materializada no segundo excerto recortado do jornal Correio da Bahia, vejamos:

(7) Tenho assistido aos interrogatórios a que tem procedido a polícia para descobrir os assassinos de Alexandre Argollo.... Dez foram os escravos que agarraram a victima, e contribuíram para o estrangulamento. O cabeça foi Severiano, feitor, e os outros foram:

Agrippa, Zafiro, Boaventura, Sabino, Gualberto, Zephirino, Marcolino, Francisco, Hemórgenes e Martinho. Este último que era o lacaio do assassinado [...] (Correio da Bahia, edição 141, p. 1, 15 de Setembro de 1878 - Hemeroteca Digital da Biblioteca Nacional).

Em 7, podemos notar que a sequência $O$ cabeça foi Severiano, feitor, e os outros foram: Agrippa, Zafiro, Boaventura, Sabino, Gualberto, Zephirino, Marcolino, Francisco, Hemórgenes e Martinho funciona no acontecimento enunciativo como uma reescritura por expansão de escravos. Verifica-se que o nome do senhor aparece enunciado de forma completa com nome e sobrenome, já os escravos são referenciados apenas pelo nome de batismo. Conforme Ferrari (2000, p. 60), o escravo era batizado na igreja e recebia um nome, simplesmente um nome de pia, um nome de batismo: José, Honório, Benedita. Nesse ato, ele era constituído como sujeito religioso e não como sujeito jurídico com sobrenome. Essa constituição o acompanhava por toda a sua vida de escravo, de forma que pouco importava o seu nome, a não ser para indicar sua relação com o senhor.

No terceiro excerto que recortamos para a análise, podemos observar essa relação de subordinação, que confirma, portanto, o que diz Freyre (1933, p. 38): “[...] Donos das terras. Donos dos homens. Donos das mulheres [...]" 
- Análise semântico-enunciativa de senhorio no âmbito da família patriarcal: o nome e a transmissão de bens

(8) No vapor Paulo Affonso, vieram de S. Cristóvão os seguintes passageiros: Francisco P. de Siqueira Sobral, com 1 escravo, dr. Silvio A. Sousa Bastos, com 1 escravo, D. Joana Vianna, José Fernandes de Oliveira, com sua senhora e 2 filhas menores, e 1 escrava. (Correio da Bahia, edição 57, p. 2, 4 de Junho de 1872 - Hemeroteca digital da Biblioteca Nacional).

Nesse excerto retirado do jornal Correio da $\mathrm{Bahia}^{16}$, no qual são anunciados os passageiros importantes que viajaram de navio, é possível identificar dois funcionamentos.

Em primeiro lugar, notamos que articulado ao nome do senhor José Fernandes de Oliveira, através da preposição com, aparece a seguinte sequência: com sua senhora e duas filhas menores, e 1 escrava. Nota-se que entre o nome do senhor e a sequência apresentada está em funcionamento uma relação de subordinação que submete ao nome do senhor, hierarquicamente e de forma coordenada através da conjunção $e$, a sua senhora, as 2 filhas e a escrava, sem citar o nome desses subordinados.

Em segundo lugar, está em funcionamento também a diferença na estrutura de nome. Observa-se que os nomes dos senhores que viajavam no vapor vinham completos, a exemplo de José Fernandes de Oliveira, enquanto sobre os escravos desses senhores é citada apenas a quantidade: 1 escravo, 1 escrava, não havendo menção de nome, nem mesmo na forma usual de nome de escravo como analisamos em 2.1.2. Ocorre nesse excerto um silenciamento que indica a condição do escravo: por um lado, podemos observar que o nome genérico escravo aparece determinado pelo nome do senhor que vem completo com sobrenome de família; o escravo que acompanha o senhor não é nomeado, nem descrito, é apenas quantificado. Esse silenciamento indica o sentido que o termo escravo tem para a sociedade, ou seja, apesar de figurar entre os passageiros (o nome dos passageiros é uma reescritura por expansão da sequência seguintes passageiros), não há necessidade de enunciar o nome, pois o principal foi dito; trata-se apenas de escravos, não se trata de sujeitos, mas objetos, bens do senhor. Por outro lado, verifica-se, guardadas as respectivas diferenças, que, assim como os escravos, no caso do senhor José Fernandes de Oliveira, com sua senhora e 2 filhas menores, e 1 escrava, o mesmo silenciamento se aplicou a membros da própria família: a esposa e as filhas.

\footnotetext{
16 Vale ressaltar que, no jornal O asteróide, no jornal Correio da Bahia e nas cartas de liberdade, o nome do senhor segue a mesma estrutura. Por outro lado, quanto à estrutura de nome de escravo, observa-se uma diferença. Quanto ao escravo, o nome era apresentado, na maioria dos registros, seguindo a terceira estrutura, trazendo, no lugar do item lexical escravo, a palavra escravizado. Em poucos casos fazia-se referência à cor, raça ou etnia, como na primeira e segunda estrutura. Nos casos registrados, as referências de cor, raça e etnia, aparecem, principalmente, quando se noticiava a concessão de liberdade feita pelos senhores, como vemos no exemplo: Hontem realizou-se n'esta cidade a liberdade de Domingos, cabra, filho de Rosa, escravizado à Antonio José dos Santos no Sapé, pela quantia de $150 \$ 000$ que foi entregue a seu senhor pelo nosso amigo sr. advogado José Joaquim Villas-Boas. Destaque-se, nesse enunciado, que o nome do senhor Antonio José dos Santos aparece completo com sobrenome de família, já o nome do escravo libertado é enunciado como núcleo articulado às sequências que o caracterizam: cabra, filho de Rosa, escravizado.
} 
A partir do exposto, vimos que senhores e escravos se diferenciam pelo nome. O nome de senhor segue a estrutura nome próprio + sobrenome de família. O de escravo apresenta, por sua vez, três formas: a) nome + raça/cor/etnia; b) raça/cor/etnia + nome; e c) classe + nome. Essa diferença nos nomes de senhores e escravos materializada nas cartas de liberdades e nos textos dos jornais baianos instaura um embate de sentidos no espaço de enunciação do Português do século XIX. Na sociedade escravocrata, o senhor era responsável pela nomeação de seu escravo. Assim o locutor-senhor de escravo, ao designar como nome próprio do escravo a sua raça, cor ou etnia, ou mesmo o indicativo da classe (escravo/liberto/forro), nomeações que também aparecem nos textos jornalísticos, estigmatiza-o, como pertencente a um grupo de pessoas que, em dado momento histórico - Brasil Escravista do Século XIX - são escravos porque são negros vindos de determinado lugar - África - tendo certa cor, preta. Ou seja, o sobrenome racial determina o nome próprio de escravo colocando-lhe uma identificação que o acompanhará por toda a vida. Por esse motivo, Guimarães (2002, p. 36) afirma que o funcionamento do nome se dá no processo social de subjetivação. Ou seja, passa a ser uma questão do sujeito (GUIMARÃES, 2002). As reescrituras e articulações mostraram que os nomes próprios dos senhores, diferentemente do nome de escravo, carregavam os sentidos de que nome de senhor era importante na sociedade, ao qual se subordinava os nomes de escravos e os nomes dos membros da família do senhor, confirmando o que diz Freyre (1933, p. 38): "o senhor não era senhor só de escravo. Era senhor total: ocupava o topo da hierarquia social, isto materializado linguisticamente no nome".

\section{Preservação e manutenção da posse dentro da família através da transmissão dos bens aos herdeiros}

Além do nome, uma outra forma de demonstrar o poder do senhor no âmbito familiar era a transmissão dos bens aos herdeiros como forma de preservação e manutenção da posse dentro da família. A estrutura familiar era predominantemente patriarcal e tinha um núcleo constituído por pai, mãe e filhos, nesta ordem hierárquica, que se complementava com a figura de outros parentes.

Destacamos para a análise da transmissão de bens aos herdeiros, como forma de caracterização do senhorio brasileiro, três aspectos principais: a) a transmissão dos bens de forma hereditária; b) a sucessão de senhorio; e c) indícios de que até a mulher assume uma importância de acordo com o nível econômico de sua família. 
- Análise semântico-enunciativa de senhorio no âmbito da família patriarcal: o nome e a transmissão de bens

\section{a) A hereditariedade na transmissão de bens}

A respeito da transmissão de bens de forma hereditária, de acordo com Santos (2013, p. 53), percebe-se que no contexto brasileiro do final do século XIX, assim como na Europa, funcionava entre os brancos (livres, senhores) o modelo de família patriarcal/ senhorial, no qual os bens eram passados de forma hereditária para os filhos, que tinham o dever de manter e aumentar as posses da família. Essa prática pode ser exemplificada através de dois exemplos.

O primeiro exemplo foi retirado de uma carta de liberdade, vejamos:

(9) Carta de liberdade do escravo Cezario, conferida por seo Senhor Francisco Xavier de Almeida Saraiva, como abaixo se declara.

Eu abaixo assignado, de minha livre e expontanea vontade, cêdo o favor da liberdade do escravo Cezario, todo direito e acção que sobre elle tenho como herdeiro cessionário do fallecido Clemente Ferreira da Rocha [...] (Carta 120: livro 21, folha 60f, 04/10/1886).

No exemplo 9, em Eu abaixo assignado, o pronome $E u$ enunciado no início da carta, referindo-se ao senhor que está libertando o escravo, é reescriturado por herdeiro cessionário do fallecido Clemente Ferreira da Rocha. Nota-se que a reescritura por substituição retoma o pronome Eu que é uma reescritura de Senhor Francisco Xavier de Almeida Saraiva. O processo de reescrituração "liga pontos de um texto com outros do mesmo texto, e mesmo pontos de um texto com pontos de outro texto [...]. Este processo, ao se dar produz sentido na medida em que ao retomar alguma expressão faz que ela signifique de outro modo [...]" (GUIMARÃES, 2007, p. 87). Assim, na medida em que herdeiro substitui senhor, registra na língua um funcionamento social/histórico, no qual os filhos do senhor herdavam, após a morte do pai, os bens pertencentes a ele, o que retoma a prática patriarcal corrente desde a Idade Antiga.

O jornal Correio da Bahia também registra esse funcionamento, como podemos ver no segundo exemplo:

(10) Concedeu-se exequatur, a fim de que possam ser transferidas nas estações competentes para o nome do menor Manuel, filho de d. Leonarda Carolina do Amaral Queiroz as apólices da dívida pública do império e os bens de raiz existentes na corte que couberam ao mesmo menor, na qualidade de herdeiro de seu pai Manoel Alves de Oliveira Queiroz, fallecido no reino de Portugal. (Correio da Bahia, edição 91, p. 1, 15 de Julho de 1877 - Hemeroteca Digital da Biblioteca Nacional). 
Em 10, podemos observar que o nome Manuel presente no enunciado para o nome do menor Manuel é reescriturado pelas sequências filho de d. Leonarda Carolina do Amaral Queiroz, herdeiro de seu pai Manoel Alves de Oliveira Queiroz. As reescrituras confirmam que os bens serão transferidos ao filho, herdeiro legítimo do pai.

A hereditariedade na transmissão dos bens era uma prática que caracterizava o senhorio brasileiro, funcionamento reconfigurado, ou a rigor, continuado (no sentido de Le Goff, 1924,) no Brasil, a partir de práticas existentes em outros senhorios como o grego, o romano e o feudal.

\section{b) Sucessão}

O senhorio brasileiro é caracterizado no aspecto da transmissão dos bens pela sucessão. Pedro (2009, p. 5) aponta que havia em funcionamento naquela sociedade uma política senhorial para a manutenção da propriedade e do domínio, mesmo após a morte do senhor, daí a importância e frequentes citações, nas cartas e nos jornais, de aspectos relacionados a partilhas, herdeiros e também à sucessão, que garantiria a continuidade do regime. Conforme Cotrim (2005, p. 54):

[...] ainda dentro desse sistema patriarcal, desenvolveu-se o costume da primogenitura, em que o filho mais velho herdava todas as terras do pai. Se a família fosse composta por mais de um filho, os outros seriam encaminhados aos estudos para se formarem médicos, advogados ou mesmo padres, caso sua formação fosse religiosa .

No excerto a seguir, podemos ver um exemplo característico envolvendo sucessão:

(11) [...] Digo eu abaixo assignado como testamenteiro do finado Liborio Joaquim da Silva que ele dito finado hera Senhor Legítimo e possuidor de hum Escravo de nome Manoel Africano [...] poderá gosar de sua liberdade como se fosse nascido do ventre branco digo do ventre mater-no, e [isso?] fica de hoje para trás [e sempre] sem que eu ou um $<$ dos $>$ meos herdeiros e sucessores pos-são [aliar] esta minha carta de liberdade pes-so as justiças de Sua Magestade Imperial que Deos Guarde haja esta [.......] e valiosa, e lhe dê todo o inteiro vigor, e se lhe faltar alguma clauzula, ou clausulas, aqui as dou por expressas e declaradas [...] (Carta 40: livro 1, folhas 115f-115v-116f, 23/05/1845 - DOVIC).

Em 11, senhor é reescriturado por substituição pelo pronome pessoal eu. Essa reescritura aparece articulada pelo conectivo ou a um dos meos herdeiros e sucessores. Destaque-se, nessa articulação, que as expressões não podem ser substituídas uma pela 
- Análise semântico-enunciativa de senhorio no âmbito da família patriarcal: o nome e a transmissão de bens

outra, ou seja, eu (senhor), não é o mesmo que herdeiro, assim como herdeiro não é o mesmo que sucessor, embora acrescentem sentidos à palavra senhor. Enquanto o sucessor era aquele que ocuparia o lugar de senhor, o patriarca que exerceria o poder e domínio sobre a família, escravos e agregados, os herdeiros eram aqueles que teriam direito a bens em determinada partilha. Podemos observar que o item lexical sucessores aparece no plural, o que indica a estabilidade do regime escravista, ou pelo menos a crença nessa estabilidade que manteria o patriarcado dentro da família.

\section{c) Importância da mulher de acordo com o nível econômico de sua família}

O papel que a mulher assume de acordo com o nível econômico de sua família é o terceiro e último aspecto que revela a importância da família e dos bens econômicos nessa sociedade. Freyre (1951, p. 82) afirma que, no Brasil, houve matriarcas apenas como equivalentes de patriarcas, isso considerando, na visão freyriana, matriarcas "aquelas matronas que, por ausência ou fraqueza do pai ou do marido, e dando expansão a predisposições ou característicos masculinóides de personalidade, foram às vezes os 'homens de sua casa'" (FREYRE, 1951, p. 82). No corpus analisado, especificamente nas cartas da liberdade e no jornal Correio da Bahia, encontramos indícios desse funcionamento, em dois exemplos.

Em primeiro lugar, consideremos, para análise, o excerto retirado de uma carta de liberdade.

(12) [...] Digo eu Ignes Rodrigues Fontoura Dona Viuva de José da Cunha Soares, que dentre os mais bens, que sou legitima Senhora, e possuidora, he bem assim a escrava Maria Silveria Nação congo, que a houve por compra feita ao Capitam Manoel Pereira Sampaio, cuja escrava pelos bons serviços que della tenho recebido he de minha livre vontade, sem constrangimento de pessoa alguma que do dia de meu falecimento em diante fique gozando de sua liberdade como se de ventre livre nassece, acompanhando me e servindo-me e servindo durante minha vi-da, não me fazendo ingrati-dam por que possa ser revogada esta alforria [...] (Carta 5: livro 2, folhas 27v-28f-28v, 28/03/1844 - Dovic).

Em 12, o nome de pessoa Ignes Rodrigues Fontoura é reescriturado pela sequência Dona Viuva de José da Cunha Soares, e logo depois por Senhora, e possuidora. Observase que o elemento Dona assim como Senhora estão grafados em maiúsculo e refere-se a uma mulher senhora de escravos. De acordo com Santos (2008), isso indica que, por ser uma sociedade patriarcal, essa mulher era herdeira de um Senhor, possuindo as duas propriedades básicas do senhorio: a posse e o domínio. Senhora, portanto, nesse enunciado, não é um pronome de tratamento (como atualmente): é uma espécie de título. 
Conforme Ferraz e Santos (2012), a palavra Dona ocupa o lugar de pronome de tratamento que, articulado à palavra Senhora, enfatiza a posição social da pessoa: Dona era pronome de uso restrito a pessoas de certa importância, isso porque dona, derivado de dominus, era no período medieval um pronome usado para se referir ao rei e a seus filhos legítimos. Entretanto, a conotação de autoridade e respeito ampliou o seu uso aos homens ricos e senhores feudais. Essa conotação se fez presente na sociedade escravocrata brasileira, daí a utilização de expressões como essas (BIDERMAN, 1973).

O segundo exemplo que confirma a importância e a ascensão da mulher dentro da família senhorial foi encontrado no jornal Correio da Bahia:

(13) Falleceu no dia 4 a exma. Sr. D. Anna Moreira de Pinho irman do major Alexandre Moreira de Pinho, senhor do engenho Jacuípe do Britto, na freguezia do Rio-fundo. (Correio da Bahia, edição 238, p. 2, 17 de Janeiro de 1877 - Hemeroteca Digital da Biblioteca Nacional).

Em 13, o nome próprio Anna Moreira de Pinho aparece articulado às expressões abreviadas exma. Sr. D. Observa-se que somente o pronome de tratamento exma aparece grafado com inicial minúscula, o que confirma que $\operatorname{Sr}$ (senhora) e $D$. (dona) funcionavam como uma espécie de título e tratamento dado apenas àquelas mulheres que eram importantes, no caso, tratava-se da irmã do major Alexandre Moreira de Pinho, senhor de engenho. A esse respeito, assim se manifesta Freyre (1951, p. 209-210):

As senhoras de engenho, desse feitio amazônico, embora mais femininas de corpo, não foram raras. Várias famílias guardam a tradição de avós quase rainhas que administraram fazendas quase do tamanho de reinos. Viúvas que conservaram e às vezes desenvolveram grandes riquezas. Quase matriarcas que tiveram seus capangas, mandaram dar suas surras, foram 'conservadoras' ou liberais' no tempo do Império.

Diante do que foi exposto, vimos que, no conjunto, um dos aspectos que caracteriza o senhorio brasileiro no âmbito da família é a transmissão dos bens aos herdeiros como forma de preservação e manutenção da posse dentro da família. A hereditariedade na transmissão dos bens, a sucessão patriarcal e o papel da mulher assumindo a posição de "homem da casa" na ausência ou fraqueza do marido demonstram a importância do clã patriarcal, que mantinha dentro da família a posse e o domínio. Dessa maneira, a transmissão dos bens aos herdeiros reiterava o poder e o prestígio já materializados nos nomes/sobrenomes dos senhores. 
- Análise semântico-enunciativa de senhorio no âmbito da família patriarcal: o nome e a transmissão de bens

\section{Considerações finais}

Por fim, respondendo à pergunta inicial, observamos, a partir das análises empreendidas, que, fundamentado no patriarcado, semanticamente, o senhor brasileiro exerce domínio na esfera familiar. Os dados demonstraram que, no tocante à estrutura linguística/lexical do nome do senhor em oposição à estrutura do nome de escravo, vimos que senhores e escravos se diferenciam pelo nome. Os nomes próprios dos senhores carregavam o sentido de que nome de senhor era importante na sociedade, ao qual se subordinavam os nomes de escravos e os nomes dos membros da família do senhor. O nome do escravo materializado nas cartas e nos jornais é uma palavra que o inclui na sociedade dando-Ihe uma identificação, mas esse nome, ao trazer indicações de raça, cor e etnia ou o indicativo de classe, o exclui de certos espaços reservados para pessoas cujos nomes tinham, por assim dizer, outra estrutura, que os identificava como "de família", como Senhores. O nome de escravo o identificava como pertencente a um grupo, a uma classe de trabalhadores, silenciando com isso a sua condição de pessoa pertencente a uma família, com pais, irmãos, etc. Assim, concordando com Guimarães (2002), pode-se dizer que disso resulta a importância do funcionamento determinativo da construção do nome próprio de pessoa: não é apenas um evento social, jurídico, é um acontecimento linguístico, enunciativo com suas consequências. A esse respeito, Santos (2008, p. 140) afirma que o escravo, mesmo se liberto, continuava a ter no nome a marca, o estigma da escravidão. Se o sobrenome de família marcava positivamente, pode-se dizer que o sobrenome "racial" surtia efeito contrário.

Além do nome, mostramos também que o senhorio brasileiro se constitui semanticamente na relação de transmissão dos bens aos herdeiros. A hereditariedade na transmissão dos bens, a sucessão patriarcal e o papel da mulher assumindo a posição de "homem da casa" na ausência ou fraqueza do marido, demonstrava a importância do clã patriarcal, que mantinha dentro da família a posse e o domínio, que reiteravam os sentidos trazidos pelo nome de família.

Através das análises feitas, vimos que o senhorio brasileiro apresenta sentidos específicos fundamentados não somente na relação senhor-escravo, mas também relacionados ao poder do senhor exercido no âmbito da família patriarcal.

\section{Agradecimentos}

Agradecemos à Universidade Estadual do Sudoeste da Bahia, ao Programa de Pós-graduação em Linguística, à Fundação de Amparo à pesquisa do Estado da Bahia e 
ao Conselho Nacional de Desenvolvimento Científico e Tecnológico por apoiarem essa pesquisa.

\section{Referências}

BIDERMAN, M. T. C.. Formas de Tratamento e Estruturas Sociais. Alfa, Marília, n. 18/19, p. 339-381, 1972.

CÂMARA Jr., J. M. Estrutura da língua portuguesa. Petrópolis: Vozes, 1987.

COTRIM, G. Condições da Escravidão Africana. In: COTRIM, G. História Global: Brasil e Geral. 6. ed. São Paulo: Saraiva, 2002. p. 54-68.

FERRARI, A. J. Nomes próprios e descrição: um estudo da descrição e do nome próprio a partir da análise de descrições presentes nos anúncios de fuga de escravos publicados nos jornais de Campinas entre 1870 e 1876. 2008. Tese (Doutorado em Linguística) Instituto de Estudos da Linguagem, Universidade Estadual de Campinas, Campinas, 2008.

FERRAZ, L. de A. N. SANTOS, J. V. Polissemia em cartas de liberdade baianas do século XIX: uma descrição semântica à luz de Bréal (1897). Seminário de pesquisa em estudos linguísticos, v. 7, p. 447-454, 2012.

FERRAZ, L. de A. N. A designação da palavra senhor: uma análise semântica do senhorio brasileiro na escravidão e sua continuidade no pós-abolição. 2014. Dissertação (Mestrado em Linguística) - Programa de Pós-graduação em Linguística, Universidade Estadual do Sudoeste da Bahia, Vitória da Conquista, 2014.

FREYRE, G. Casa-grande e senzala. 47. ed. São Paulo: Companhia das Letras, 2003 [1933].

FREYRE, G. Sobrados e Mocambos: decadência do patriarcado e desenvolvimento do urbano. 15. ed. São Paulo: Global, 2007 [1951].

GUIMARÃES, E. Análise de Texto: Procedimentos, Análises, Ensino. Campinas: Editora RG, 2011.

GUIMARÃES, E. A enumeração: funcionamento enunciativo e sentido. Caderno de Estudos Linguísticos, Campinas, v. 51, n. 1, p. 49-68, jan.-jun. 2009. 
- Análise semântico-enunciativa de senhorio no âmbito da família patriarcal: o nome e a transmissão de bens

GUIMARÃES, E. Semântica do Acontecimento: um estudo enunciativo da designação. Campinas: Pontes, 2002a.

GUIMARÃES, E. Os limites do sentido. 2. ed. Campinas: Pontes, 2002b [1995].

GUIMARÃES, E. Domínio semântico de determinação. In: GUIMARÃES, E.; MOLLICA, M. C. (org.). A palavra: forma e sentido. Campinas: Pontes Editores, RG Editores, 2007. p. 77-96.

GUIMARÃES, E. Enunciação e história. In: GUIMARÃES, E. História e Sentido na Linguagem. Campinas: Pontes, 1989.

LE GOFF, J. Memória. In: LE GOFF, J. História e Memória. Campinas: Editora da UNICAMP, 1994 [1924]. p. 423-477.

MATTOSO, K. M. Q. Ser escravo no Brasil. São Paulo: Brasiliense, 1982.

PEDRO, A. Liberdade sob condição: alforrias e política de domínio senhorial em Campinas, 1855-1871. 2009. Dissertação (Mestrado em História) - Instituto de Filosofia e Ciências Humanas, Universidade Estadual de Campinas, Campinas, 2009.

SANTOS, D. M. Da liberdade à tutela: uma análise semântica do caminho jurídico percorrido por filhos de ex-escravas no Brasil pós-abolição. 2013. Dissertação (Mestrado em Linguística) - Programa de Pós-graduação em Linguística, Universidade Estadual do Sudoeste da Bahia, Vitória da Conquista, 2013.

SANTOS, J. V. Liberdade na escravidão: uma abordagem semântica do conceito de liberdade em cartas de alforria. 2008. Tese (Doutorado em Linguística) - Instituto de Estudos da Linguagem, Universidade Estadual de Campinas, Campinas, 2008.

SANTOS, J. V.; NAMIUTI, C. DOVIC (Documentos Oitocentistas de Vitória da Conquista e região). Corpora Eletrônicos. UESB. Vitória da Conquista, 2014. 
COMO CITAR ESTE ARTIGO: FERRAZ, Liliana de Almeida Nascimento; SANTOS, Jorge Viana. Análise semântico-enunciativa de senhorio no âmbito da família patriarcal: o nome e a transmissão de bens. Revista do GEL, v. 18, n. 1, p. 35-55, 2021. Disponível em: https://revistadogel.gel.org.br/

Submetido em: 10/12/2020 | Aceito em: 23/01/2021. 